\begin{tabular}{|l|r|r|}
\hline An International Biannual Open Access & ISSN: 2395-3160 (Print) \\
Peer-Reviewed/Refereed Journal & ISSN: 2455-2445 (Online) \\
JOURNAL OF GLOBAL RESOURCES & $\begin{array}{c}\text { IST } \\
\text { Published by : ISDESR, Jaipur, India }\end{array}$ & January 2022, Volume 08 (01) \\
DOI Prefix: 10.46587/JGR \\
\hline
\end{tabular}

02

\title{
REDUCING LOCAL ANTHROPOGENIC ENVIRONMENTAL CHANGE MAY REDUCE GLOBAL EMERGING DISEASES
}

\author{
Mahmood Yekeh Yazdandoost \\ Advisor, Department of Environment (DoE), Iran \\ Email: yazdandoost3000@gmail.com
}

How to cite this paper:

Yazdandoost, Mahmood Yekeh (2022) Reducing local anthropogenic environmental change may reduce global emerging diseases, Journal of Global Resources, Vol. 08 (01)

DOI:

10.46587/JGR.2022.v08i01.002

Received: 22 Sep. 2021

Reviewed: 14 Oct. 2021

Revised: 03 Nov. 2021

Final Accepted: 14 Nov. 2021

\begin{abstract}
Ecological values of landscapes, like; biodiversity, connectivity and resilience capacity provide, biological well-being and cultural and economic development, which all needed for human development and health. As a result of rapid development, unplanned urbanization went against human will and health being, producing novel emerging diseases. For identifying the relationship between anthropogenic environmental changes and emerging diseases, the present study has considered the impact of ecological disconnectivity on environmental health and global emerging diseases.
\end{abstract}

Key words: Ecological Connectivity, Environmental Change, Emerging Diseases, Anthropogenic Impact.
OPEN O A C ES S

Freely available Online

www.isdesr.org 


\section{Introduction}

The planet Earth is experiencing very harsh environmental changes through human activities (Vitousek, P. M., 1994; Tilman, D., 1999). Anthropogenic Environmental Changes (AEC) in landscapes, like fragmentation of ecosystems, has led to emergence of diseases, and sometimes in a number of conditions novel diseases (Woolhouse et al., 2005; Jones et al., 2008). The species diversity relations due to the course of evolutionary interactions occur within endemic/local community. In return, this diversity in species richness and composition can also influence the transmission mode of pathogens. Within natural ecosystems, parasites without dispute are main player in shaping of the endemic/local species assembly. Regarding non-specialized or multi-species system, the pathogen diversity in reservoir hosts will have important outcome on the transmission of diseases (LoGiudice et al., 2003). Moreover, the potential reservoir species has various capacities to multiply the pathogens and transmit the disease. The vector species assembly also presents important role in disease transmission (Schmidt and Ostfeld, 2001). Among dilution hosts, some species function as ecological pitfall for the pathogens or vectors.

The pathogens are parts of ecosystems; they are embedded in trophic webs and reproduce in defined ecosystems or habitats (Horwitz and Wilcox, 2005). That's why any change in landscape structure would have considerable impact on ecosystem/human health. The pandemics of SARS and avian influenza in recent years and now COVID-19 indicate how important is emerging and novel diseases and how these diseases impact health, communication and economic development. Wildlife populations are linked in the chain of pathogen emergence, forming the reservoirs from which Zoonotic diseases may emerge, causing either localized outbreaks (epizootics) or affecting populations on global scales (panzootics). Most human Emerging Infectious Diseases (EIDs) listed by the Institute of Medicine (Lederberg et al., 1992) are Zoonotic. Anthropogenic changes to wildlife habitat, like; habitat destruction and fragmentation, increase the flow of pathogens from wildlife reservoirs and thereby foster disease emergence in humans.

Wildlife EIDs threaten biodiversity, human health, communication, behavior, culture and wellbeing in a complex inter-related manner. To understand their impact will require broad integration and an understanding of how changes in human behavior, urban structure, agricultural development, demography and economy alter pathogen transmission within the human-domestic animal-wildlife continuous sequence (Daszak et al., 2000a). Pandemics and other emerging zoonoses cause widespread human suffering and represent an existential threat to the public health across the planet. Without preventative strategies, pandemics would have more devastating impact on human society including global economy and sustainable development.

Land-use change at the local level, like; deforestation, human settlement in primarily wildlife habitat, the growth of crop and livestock production and urbanization together, would significantly create global driver of pandemics. Land-use change creates synergistic effects with climate change (forest loss, heat island effects, burning of forest to clear land) and biodiversity loss that in turn has led to important emerging diseases. Destruction of habitats and encroachment of humans and livestock into biodiverse habitats provide new pathways for pathogens to spill over and increase transmission rates. In this regard, human health considerations are largely unaccounted for in landuse planning decisions. 
The underlying driver of pandemics is mostly considered to be local with global impact that account for biodiversity loss, global warming and climate change. It may cause significant outbreak of disease with high fatality rate. Biodiversity loss associated with disruption of landscapes can lead to a high danger of zoonotic transmission. For pandemic prevention, control and response measures, an efficient transformative change with policy options would be needed. There is considerable document that the causative agent of almost all recent EIDs are massive environmental and socioeconomic changes that modify the rates of contact reservoir and people in transmission of pathogens (Jones, K. E. et al., 2008; Allen, T. et al., 2017). Various mechanisms explain how ecosystem disruption and biodiversity reduction affect disease occurrences and emergence. The dilution effect studied in detail indicates, in ecosystem with high biodiversity assemblage, pathogens would have less expectancy to find suitable hosts to establish and transmit disease (Schmidt and Ostfeld, 2001; Ostfeld and Keesing, 2012).

The emerging disease regulation may also happen through prey-predation relation that affect the populations of vectors or otherwise hosts in the community (Levi, T. et al., 2012; Sokolow, S.H. et al., 2015). Also, urban structure with the municipality/health infrastructural deficiencies, such as poor sanitation, lack of proper disposal of wastes, air pollution, population congestion and lack of adequate health services and socio-cultural limitations may lead to some contagious infectious diseases. Thus, EIDs are the interacting outcome of the pathogens, vectors, hosts and their surrounding environment. However, as the environmental factors by governing ecological systems influence the infectious diseases, on the contrary, any change in the state of EIDs can themselves bring about disruption in ecosystem functionality and services.

\section{Method}

The methodology used is the multi-ecosystem examinations exposed to the major anthropogenic changes against the reference sites in which the ecosystems are unchanged or minimally agitated. Data collection is based on monitoring and observation.

\section{Geographical Location}

The Hyrcanian mixed forests ecoregion. It is a temperate broadleaf and mixed forests biome, covering about 55,000 square kilometers, adjacent the shores of the Caspian Sea. The natural vegetation is temperate deciduous broadleaved forest. The large mammals in ecoregion are the leopard, lynx, brown bear, wild boar, wolf, golden jackal, jungle cat, badger, otter, etc. The existence of unique and endemic biodiversity makes the Caspian Hyrcanian forests a priority location for sustainable conservation. With knowing the importance of conservation in this ecoregion, unfortunately the ecological connectivity and habitats are threatened by conversion of forests into agricultural land practices, poaching and unsustainable development.

\section{Results and Discussion}

The result indicates, as many parts of the forest get disconnected by logging, road construction, building of houses and other activities, also poaching of precious species, the forest can't deliver the ecological services as before, eg., a continuous rain for a few days create severe flooding inundation, which disturbs local community and create lose of properties even in neighbouring towns. Moreover, the migratory bird's community richness and abundance gets impacted by all these adverse activities.

Also, there are some reports that the disease occurrence in wildlife has increased in compare with previous years, because forest resiliency got hampered. 
In recent years we have seen fungal pathogens like; Biscogniauxia mediterranea and Calonectria pseudonaviculata gets opportunity to infect major parts of forests and reducing the quality and productivity of the forests goods and services. Also, Tortrix viridana (green moth), Geometridae (caterpillar), Lymantria dispar (gypsy moth), Cryptococcus fagisuga (woolly beech scale), Diplodia pinea (fungus), Rhytisma acerinum (fungus), Armillaria mella (honey fungus- plant pathogen), and Viscum spp. (plant poisonous to humans) are infesting in forests and creating devastating problems.

As a result, by now we have understood, anthropogenic environmental modifications bring about environmental changes, sometimes with irreversible environmental damage, like; extinction of species (Hautier et al., 2015; Lewis and Maslin, 2015). Most EIDs are driven by anthropogenic activities. In the sense, humans by modifying the habitats and ecological systems, created the conditions for pathogens to spread into new hosts and ecological niches (Taylor et al., 2001). Direct anthropogenic drivers that affect diseases outbreak include: wildlife habitat destruction, deforestation, conversion of land, diversion of surface water, unplanned urbanization, chemical deposition, solid waste disposal and air pollution. That's why, due to human-induced environmental changes, our planet has entered a new geological epoch termed the Anthropocene (Crutzen and Stoermer, 2000).

According to the $\mathrm{WHO}$, environmental threats to human society include: global warming and climate change, ozone depletion, loss of biological diversity, changes in hydrological systems, land degradation, urbanization, and stresses on food-producing systems (WHO, 2017). Also, transportation is the greatest risks for the rapid spread of infectious diseases (Jaffry et al., 2009). Particularly in the places with high biodiversity and rapid ecological disturbance the chances for the emergence of new pathogens are quite high (Jones et al., 2008). The anthropogenic environmental alteration is the most significant driver of wildlife, domestic animal and human EIDs. The study of EIDs requires an integrated, multidisciplinary approach (Daszak et al., 2000a). Ecological restoration, which is critical for conservation, climate adaptation and provision of ecosystem services, should integrate health considerations to avoid potential increased disease risk resulting from increased human-livestock-wildlife contact.

There are comprehensive evidences that climate change induced by human activities and style of life impact ecological well-being and human health. For example, when the heat waves happen, there would be considerable additional deaths that one need to decide how to reduce these risks. Moreover, the temperature change will bring other consequences, like; droughts, floods, fires, vector-borne diseases and poor agricultural production which leads to mal-nutrition and poverty. Also, an increase of ozone level in troposphere would increase the cardio-respiratory diseases and mortality. There are scientific evidences that while host diversity increases, the infection risk decreases in a focal species. As a result, the greater host diversity may reduce the retention of the infection in a community (Keesing et al., 2010; Wood et al., 2014).

Moreover, the modification of ecosystems and natural processes may also lead to alteration of diseases incidence, because ecosystems provide some specific functions and any disturbance in the regulation function of ecosystems may favor the population of some vectors or hosts to flourish. 


\section{Recommendations}

- Incorporating Health Impact Assessments (HIAs) in major development and land-use projects.

- Developing programs based on effective habitat conservation measures.

- Enabling transformative change to reduce agricultural expansion and trade.

- Educating communities in emerging wildlife infectious diseases.

- Conducting disease surveillance of wildlife in the trade.

- Enhancing law enforcement collaboration on illegal wildlife trade.

- Improving understanding of the relationship between ecosystem degradation and restoration and landscape structure, and the risk of emerging disease.

- Considering economic analyses of return-on-investment for programs that reduce the environmental changes that lead to pandemics.

- Valuing Indigenous People (VIP) and Local Communities' engagement and knowledge in pandemic prevention programs.

\section{Conclusion:}

The ecosystems connectivity in the landscape delivers the functionality, productivity and diversity of the natural environment. Multiple Complex Changes (MCC) in this arrangement; would reduce the Earth's operating system and handicaps the environmental quality to serve specific functions. The balance in biodiversity composition like, hosts, predators, preys, vectors, and parasites deliver indispensable services from ecological systems which controls EIDs. There are links in the chain of emergence of human and domestic animal diseases with pathogens, habitats and environmental changes shared between these populations. Anthropogenic drivers of local environmental change may have different impact at global scales. For instance, when we locally replace natural vegetation for agriculture, we reduce ecosystems services and increase the rate of species extinction with large impact on global climate change. Moreover, landscape disruption, deforestation, urbanization and desertification are main drivers of large life-threatening infectious diseases. In most cases, these drivers cause a new, sometimes devastating challenge.

A comprehensive surveillance system should be designed to prevent environmental infectious diseases by identifying risks to ecological and human health and well-being. However, to understand how diseases from wildlife reservoir hosts will respond to drivers of change requires a series of investigation on ecological examination of diseases dynamics. Many diseases display complexities with multi-host species and multi-infectious agents that require novel knowledge and methods to control them. In multiple host species the infectious agent may be maintained by several host species, contributing to the maintenance of transmission. Moreover, pathogens dynamics totally depends on the dynamics of the species diversity in the community. In this regard, the present alteration of the forest ecological system may accelerate the spread of infectious diseases, because vectors and reservoirs may gain more favorable environmental condition. Therefore, ecosystem disruption accounts for biodiversity reduction, enhancing the risk of disease from primary reservoir. The EIDs continue to challenge global health now as well as in future. To respond to EIDs effectively, well planned strategy with global coordination effort should be implemented.

Acknowledgement: All the scientific literatures released by academia, UN and other agencies including Department of Environment that have been used in this research paper are highly appreciated. 


\section{References}

1. Allen, T. et al., (2017). Global hotspots and correlates of emerging zoonotic diseases. Nat Common 8,1124.

2. Crutzen, P.J., Stoermer, E.F., (2000). International Geosphere-Biosphere Programme, 41:1718.

3. Daszak, P. et al., (2000). Emerging infectious diseases of wildlife threats to biodiversity and human health. Science 287, 443-449.

4. Hautier, Y. et al., (2015). Anthropogenic environmental changes affect ecosystem stability. Science 348(6232):336-340.

5. Horwitz, P., Wilcox, B.A., (2005). Parasites, ecosystems and sustainability: an ecological and complex systems perspective. Int. J. Parasitol., 35(7):725-32.

6. Jaffry, K.T. et al., (2009). Zoonoses. International Journal of Agric Biol. 11:217-220.

7. Jones, K. E. et al., (2008). Global trends in emerging infectious diseases. Nature 451, 990-993.

8. Keesing, F. et al., (2010). Impacts of biodiversity on the emergence and transmission of infectious diseases. Nature 468, 647-652.

9. Lederberg, J. et al., (1992). Emerging Infections: Microbial Threats to Health in the United States. Institute of Medicine. National Academy Press, Washington D.C.

10. Levi, T. et al., (2012). Deer, predators, and the emergence of Lyme disease. PNAS. https ://doi.org/10.1073/ pnas.12045 36109 .

11. Lewis, S.L. and Maslin, M.A., (2015). Defining the Anthropocene. Nature 519(7542):171-180.

12. LoGiudice, K. et al., 2003. The ecology of infectious disease. Proceeding National Academy of Science, USA 100, 567-571.

13. Ostfeld, R.S. and Keesing, F., (2012). Effects of host diversity on infectious disease. Annu Rev Ecol Evol Syst., 43(1):157-82.

14. Schmidt, K.A. and Ostfeld, R.S., (2001). Biodiversity and the dilution effect in disease ecology, Ecology 3, 609-619.

15. Sokolow, S.H. et al., (2015). Reduced transmission of human schistosomiasis after restoration of a native river prawn that preys on the snail intermediate host. Proceeding National Academy Science, 112(31):9650-5.

16. Taylor, L.H. et al., (2001). Risk factors for human disease emergence. Phil. Trans. Soc. Lond. B., 356, 983-989.

17. Tilman, D., (1999). Proceeding National Academy Science. USA 96, 5995-6000.

18. Vitousek, P. M., (1994). Ecology 75, 1861-1876.

19. WHO (2017). Global environmental change. Available online: (http://www.who.int/globalchange/environment/en/).

20. Wood, C.L. et al., (2014). Does biodiversity protect humans against infectious disease? Ecology, 95(4):817-32.

21. Woolhouse, M.E.J. et al., (2005). Emerging pathogens: the epidemiology and evolution of species jumps, TREE 20, 238-244. 